\title{
La práctica de la arquitectura contemporánea en las ciudades históricas españolas. Notas para una aproximación histórico-urbanística
}

\author{
María A. Castrillo Romón y MARina JimÉnez JimÉneZ ${ }^{1}$
}

\section{The Practice of Contemporary Architecture in Spanish Historical Cities. Notes for an Urban History Approach}

\begin{abstract}
RESUMEN
La perspectiva conservacionistamonumental ha dominado desde sus orígenes la gestión urbanística de las ciudades históricas en España y, con mucha frecuencia, ha desembocado en la imposición de un cierto mimetismo a los proyectos de edificios de nueva planta ubicados en entornos históricos. Sin embargo, desde hace aproximadamente dos décadas, esta perspectiva conservacionista-monumental viene siendo compatible, incluso en los ámbitos monumentales más reconocidos (ciudades del patrimonio mundial, conjuntos histórico-artísticos), con la construcción de edificios singulares emblemáticos de la arquitectura contemporánea más reciente. Este artículo busca aportar elementos de comprensión de este fenómeno aparentemente paradójico a partir del análisis de las políticas urbanas más extendidas sobre los centros históricos y de las realizaciones en algunas de las ciudades patrimoniales más relevantes de

Castilla y León.

Los resultados obtenidos apuntan una reformulación de los mecanismos de conservación/destrucción de la ciudad
\end{abstract}

\begin{abstract}
From its origin the conservationistmonumental perspective has dominated the city-planning management of the historical spanish cities and, very frequently, it has ended in the imposition of a certain mimesis with new bulding's projects located on the historical areas. Nevertheless, from approximately two decades, this conservationistmonumental perspective comes being compatible, with the construction of emblematic singular buildings by the most recent contemporary architecture, even, in the most recognized monumental urban areas. This article approaches some of understanding elements of this apparently paradoxical phenomenon in Spain from the analysis of the current urban policies on the historical centers and the accomplishments in some of the most excellent patrimonial cities of Castilla y León.

The obtained results suggest a reformulation of the historical city's conservation/destruction mechanisms in which the work of famous architects of the national and international scene articulates and contributes to a increase the cultural and real estate value of the
\end{abstract}

1 Instituto Universitario de Urbanística de la Universidad de Valladolid. Escuela Técnica Superior de Arquitectura. Avda de Salamanca, s/n. 47014 Valladolid. Tel.: (0034) 9834234 65. mariacr@arq.uva.es 
histórica en los que se articula la obra de reputados arquitectos de la escena nacional e internacional, que contribuiría a la revaloración cultural y, por ende, inmobiliaria de los centros históricos por una doble vía: por un lado, mediante el reconocimiento del patrimonio edificado desde una perspectiva monumental «avanzada» que incorpora, junto al patrimonio convencional (conjunto histórico-artístico, $\mathrm{PECH}, \mathrm{BIC}$, catálogo...), un cierto "patrimonio contemporáneo», y, por otro lado, por la promoción de equipamientos culturales de prestigio albergados en esas nuevas arquitecturas.

Se concluye que, por las dos vías identificadas, se contribuye a una progresiva conversión de los centros históricos en espacios segregados tanto socialmente («gentrificados») como funcionalmente (especializados en turismo cultural) y que esta conversión materializa la mercantilización del patrimonio edificado identificada por Françoise

Choay. Este fenómeno permitiría comprender la coexistencia de criterios aparentemente contradictorios en relación con la inserción de arquitecturas contemporáneas en áreas urbanas protegidas.

PALABRAS CLAVE: patrimonio urbano, ciudad histórica, arquitectura contemporánea, mercantilización del patrimonio. historical areas by a double way: on one hand, by a new «advanced" recognition of the built heritage, which one includes as much conventional heritage ("conjunto historico-artistico", $\mathrm{PECH}, \mathrm{BIC}$, catalogue...) as «contemporary heritage»; and, on the other hand, by the promotion of prestigious cultural equipment within those new architectures.

One concludes that, by the two identified ways, a progressive conversion of the historical centers in gentrificated and functionally specialized (cultural, tourism) spaces contributes to realise the merchandising of the built patrimony identified by Françoise Choay. This phenomenon would make possible to understand the coexistence of apparently contradictory criteria with the insertion of contemporary architectures in preserved historic urban areas.

\section{KEY WORDS:}

urban heritage, historical city, contemporary architecture, heritage merchandising.

\section{1. «ARQUITECTURA MILAGROSA» EN CENTROS HISTÓRICOS: ¿UNA PARADOJA CONSERVACIONISTA?}

Las ciudades españolas, como las europeas, están sumergidas en una lógica de competitividad en la cual cobra sentido un fenómeno al que ya no se sustraen ni siquiera las ciudades medias y pequeñas ${ }^{2}$. Cada cual compite a su escala y dentro de sus posibilidades pero, en todos los casos, una estrategia habitual es, precisamente, dotarse de edificios emblemáticos que no lo son sólo por su uso singular portador de cierta centralidad urbana o territorial (centros de negocios y comer-

\footnotetext{
2 Ciudades, 5 (1999) «Ventajas urbanas y competitividad entre ciudades».
} 
ciales, auditorios, palacios de congresos, museos...) sino también (y esto es fundamental) por ser obra de una arquitecto o una firma de arquitectos de prestigio.

Las estrategias basadas en el impacto mediático de un gran equipamiento firmado por un afamado arquitecto pretenden alcanzar sistemáticamente toda una serie de efectos políticos (prestigio, reelección) y económicos (dinamización, cambios en la economía urbana, mejora de la posición en el sistema de ciudades) que todos bien conocemos por la propaganda que de ello hacen nuestros gobiernos locales. En España, este fenómeno ha sido bautizado por sus apóstoles como «efecto Guggenheim», si bien, considerando el fenómeno en su conjunto y en su contexto —el paroxismo del boom edificador de 1994-2007-, son tantos y tan beneficiosos los efectos que se ha pretendido atribuir a la construcción de este tipo de edificios que más valdría referirse a ellos, como irónicamente hace Llátzer Moix en un libro reciente, como «arquitectura milagrosa» ${ }^{3}$.

Desde mediados de los noventa, en virtud de ese marketing urbano, nuestros ayuntamientos luchan denodadamente por incorporar a sus ciudades «piezas» casi como si de coleccionistas se tratase- de arquitectos de prestigio reconocido. Esta tensión reciente de las políticas urbanas en torno a las más célebres firmas arquitectónicas del momento ha alcanzado también a los ámbitos históricos de las ciudades, lo cual no deja de resultar paradójico si se considera la perspectiva conservacionista-monumental que ha dominado desde sus orígenes la gestión urbanística dichos centros en España y que, con mucha frecuencia, ha supuesto la institucionalización en ellos de un cierto mimetismo entre el común de las nuevas edificaciones.

Desde hace aproximadamente dos décadas, esta perspectiva conservacionista-monumental viene siendo compatible, incluso en los ámbitos monumentales más selectos (ciudades del patrimonio mundial, conjuntos histórico-artísticos), con la construcción de edificios singulares emblemáticos de la arquitectura contemporánea más reciente, en los que el mimetismo con el entorno desaparece o, como mucho, se limita a un problema de materiales de revestimiento. Este artículo esboza algunas ideas, algunas posibles pistas para comprender este fenómeno aparentemente paradójico.

Nos apoyamos para ello en el análisis de las políticas urbanas más extendidas sobre los centros históricos, ilustrándolas y contrastándolas con realizaciones habidas en algunas de las ciudades históricas más relevantes de Castilla y León. Avalan la validez de esta elección, por un lado, la importante riqueza y abundancia del patrimonio urbano de esta comunidad autónoma, y, por otro, el número y la relevancia de edificios recientemente construidos por arquitectos de fama internacional en algunos de sus más reconocidos recintos urbanos históricos.

\footnotetext{
3 MOIX, Llàtzer, Arquitectura milagrosa: hazañas de los arquitectos estrella en la España del Guggenheim. Barcelona: Anagrama, 2010.
} 
Nuestra hipótesis es que, desde la década de 1990, la arquitectura contemporánea de prestigio está siendo interpretada por las políticas urbanísticas sobre las ciudades históricas dentro de la lógica «monumentalista» dominante desde hace más de medio siglo en Europa.

En España, en general, la presencia en los tejidos urbanos antiguos de la arquitectura contemporánea (de prestigio o no) ha sido, tradicionalmente, y contra lo que pudiera parecer a primera vista, acorde con los criterios conservacionistas consolidados en las políticas urbano-patrimoniales desde mediados del siglo XX, si bien ha adoptado modalidades diferentes según los diferentes momentos del proceso contemporáneo de conservación/destrucción de las ciudades históricas identificados por Álvarez Mora4.

Desde esta perspectiva, la actual irrupción en tejidos urbanos históricos de arquitecturas contemporáneas - ya se trate de remodelaciones o construcciones de nueva planta, o, siguiendo la taxonomía propuesta por Benevolo, de arquitecturas de «tradición moderna» o de las «innovadoras» ${ }^{5}$ - no supone una contradicción esencial en la evolución urbanística seguida hasta la fecha por aquéllos, sino que constituye la expresión o modalidad última de ese proceso que viene teniendo lugar en las ciudades históricas de toda Europa desde mediados del siglo XX.

Además, este fenómeno reciente ha confluido o, mejor — si se nos permite la metáfora-, ha entrado en resonancia con otros procesos específicos que vienen teniendo lugar en los centros históricos desde hace más de medio siglo. Así, en los últimos años, la tendencia de las políticas urbanas a instrumentarse con grandes arquitecturas contemporáneas de prestigio ha confluido y redoblado la «terciarización» y la «elitización» (gentrification) de aquéllas áreas.

Para argumentar estas hipótesis resulta necesario, primero, hacer una breve descripción genérica de las dos líneas de pensamiento urbanístico europeo que han dominado la cuestión de los centros históricos desde hace más de 40 años. Una de ellas, la que asocia ciudad histórica con excepcionalidad urbanística y primacía de la lógica de conservación, ha sido y continúa siendo, como veremos, hegemónica en Europa y también en España.

En segundo lugar, centrándonos en España y en Castilla y León, nos proponemos ahondar en los presupuestos de las políticas aplicadas a los centros históricos en las décadas centrales del siglo $\mathrm{XX}$ y en el rol que han asignado, en relación con la evolución de esos espacios, a la arquitectura contemporánea.

4 ÁLVAREZ MORA, Alfonso, Conservación del patrimonio, restauración arquitectónica y recomposición elitista de los espacios urbanos históricos: Lección de apertura del curso académico 1995-96. VaIladolid: Universidad de Valladolid, 1995.

5 «La arquitectura se pierde», entrevista realizada el 30/07/2006 por Francesco Erbani a Leonardo Benevolo. http://metrovitoria.blogspot.com/2009/02/entrevista-com-leonardo-benevolo.html ó

http://miradaglobal.com/index.php?option=com_content\&view=article\&id=429\%3Ala-humanizaciondel-ambiente\&catid=31\%3Atemas\&ltemid=35\&lang=es (consultado: 28 de diciembre de 2010). 
La práctica de la arquitectura contemporánea en las ciudades históricas españolas...

Sólo de esta manera estaremos en condiciones, en un tercer momento, de poder valorar con precisión el significado de la irrupción actual de la arquitectura contemporánea en relación con procesos característicos seguidos por estos ámbitos protegidos.

Las ideas y materiales gráficos empleados en este trabajo han surgido en su mayor parte a partir de resultados y reflexiones generados por el Instituto Universitario de Urbanística de la Universidad de Valladolid en el desarrollo de distintas líneas y proyectos de investigación y de varios programas de doctorado y publicaciones $^{6}$. Más concretamente, es deudor del proyecto de investigación dirigido por Alfonso Álvarez Mora, «Producción de la vivienda y recuperación residencial en el marco territorial de los centros históricos" (2007-2009)7, y del Atlas de Centros Históricos de Castilla y León (2009) dirigido por Juan Luis de las Rivas ${ }^{8}$.

\section{LA «CUESTIÓN DE LOS CENTROS HISTÓRICOS» EN EUROPA: CONSERVACIÓN «ACTIVA» VS CONSERVACIÓN «PASIVA»}

Los centros históricos (en su sentido estricto: tramas urbanas históricas que acogen funciones de centralidad) se constituyeron objetivamente con la emergencia de la ciudad industrial europea, esto es, en el primer estadio de la formación de la ciudad capitalista. En este momento en que la ciudad desborda impetuosamente los límites que la habían contenido, la extensión urbana se configurará como primera periferia y la ciudad preexistente (la «ciudad histórica»), en virtud del modelo dialéctico sobradamente conocido, se verá a menudo reconvertida, al menos parcialmente, como centro de la entidad urbana resultante.

Los centros históricos surgen, pues, como un fenómeno espacial asociado al surgimiento de la ciudad moderna. Esto quiere decir que su configuración toma lugar, en una grosera aproximación cronológica, hacia mediados del siglo XIX, cuando los espacios históricos dejaron de ser la única ciudad, la «ciudad total», y se transformaron, cuando menos en parte, en centros urbanos por medio de una serie de procesos y mecanismos de intervención bien conocidos, en los que fueron determinantes la consolidación de la burguesía como clase dominante y la instau-

\footnotetext{
${ }^{6}$ Destacan, además de los proyectos y publicaciones que se citan a lo largo de este artículo, los programas de doctorado "Ciudad, territorio y patrimonio» $\mathrm{y}$ «Problemas de la arquitectura y la ciudad modernas", así como AA.VV. Planificación en centros históricos: jornadas celebradas en Segovia, 21-22-23 marzo 1991. Valladolid: Universidad de Valladolid, 1993; y AA.VV. Planes Especiales. Segovia. Segovia: Ayuntamiento de Segovia, 1991.

7 «Producción de la vivienda y recuperación patrimonial en el marco territorial de los centros históricos. A propósito de las economías urbanas que se impulsan, o se minoran, como consecuencia de las declaraciones, como bienes e interés cultural, de los centros históricos». Proyecto de investigación financiado por el Ministerio de Educación y Ciencia, Plan Nacional de I+D+I (Ref. SEJ2006-01530/SOCI), desarrollado en 2006-2009 por un equipo del Instituto Universitario de Urbanística de la Universidad de Valladolid dirigido por el Dr. Alfonso Álvarez Mora.

${ }^{8}$ RIVAS, Juan Luis de las (coord.), Atlas de Conjuntos Históricos de Castilla y León. [Valladolid], Consejería de Cultura y Turismo, [2009].
} 
ración de la renta del suelo como «regulador» de las transformaciones espaciales urbanas $^{9}$. Esos cambios estructurales se expresaron en importantes transformaciones físicas y sociales perceptibles, en mayor o menor medida, sobre todas las ciudades de Europa. La profundidad y contradicciones de estas transformaciones urbanas en el contexto de la cultura moderna emergente darán lugar a una preocupación tensionada entre la consideración de la gravedad de los «males» de los centros históricos (problemas higiénicos, funcionales, sociales y políticos) y el reconocimiento de sus diversos valores (histórico, artístico y económico, de uso y de cambio).

Entre estos dos polos arraigará, en última instancia, un debate disciplinar específico en torno a los objetivos y criterios de intervención sobre estos espacios históricos sometidos a fuertes tensiones de transformación. Pero ese debate no podrá sustraerse del devenir de la «cuestión patrimonial» que caracteriza la cultura moderna, de manera que los términos del debate variarán y se matizarán en función de la concepción de patrimonio urbano operativa en cada momento de la historia urbanística ${ }^{10}$.

Interesa aquí el momento en que ese debate se cruza con la arquitectura contemporánea, momento cuyo umbral identificamos grosso modo hacia la década de 1950, cuando, por un lado, cobra vigor la llamada «cuestión de los centros históricos» y, por otro, se identifica convencionalmente la frontera cronológica entre la arquitectura moderna y la «contemporánea».

En adelante, nos referiremos a la «arquitectura contemporánea» como aquella realizada con posterioridad a 1950 y que se expresa en lenguajes arquitectónicos que pretenden ser originales de su momento histórico. Por otro lado, utilizaremos la expresión «centros históricos» para referirnos a las áreas que han asumido funciones de centralidad dentro de lo que convencionalmente se viene denominando "ciudad histórica», esto es, los trazados y tejidos urbanos anteriores al siglo XIX.

\subsection{Corrientes de pensamiento urbanístico sobre los centros históricos a partir de 1950}

El debate urbanístico en torno a la intervención sobre los centros históricos se desarrolla, desde la década de 1950, en torno a dos grandes ejes con un mismo punto de partida nominal: dar respuesta a la destrucción del patrimonio urbano ${ }^{11}$.

\footnotetext{
9 ÁLVAREZ MORA, Alfonso y ROCH, Fernando, Los centros urbanos: hacia la recuperación popular de la ciudad. Madrid, Nuestra Cultura, 1980. También ÁLVAREZ MORA, Alfonso, La remodelación del centro de Madrid. Madrid: Ayuso, 1978.

10 CHOAY, Françoise, Alegoría del patrimonio. Barcelona: Gustavo Gili, [2007].

11 ÁLVAREZ MORA, Alfonso, «La cuestión de los centros históricos. Generaciones de planes y políticas urbanísticas recientes», en ÁLVAREZ MORA, Alfonso y CASTRILLO ROMÓN, María (coords.), Ciudad, territorio y patrimonio. Materiales de investigación. Valladolid: Universidad de Valladolid, Instituto Universitario de Urbanística, 2001. Aunque datando de 30 años y circunscrito al ámbito italiano,
} 
El primero de estos ejes constituye el modelo conocido como «nueva cultura de la ciudad»: reconoce los valores históricos de los centros pero prioriza una perspectiva social y territorial en la interpretación del patrimonio urbano. La intervención que se sigue de ello tendrá como uno de sus presupuestos básicos la integración social, económica y funcional de los centros históricos como una pieza más de la estructura urbana de la ciudad. El caso paradigmático es, sin duda, la política urbanística elaborada para el centro histórico de Bolonia a partir de $1959^{12}$.

El otro eje de pensamiento prioriza la consideración de la excepcionalidad histórica y urbana de estas áreas, con lo que la intervención propugnada se basa en su aislamiento y diferenciación dentro del conjunto de la ciudad con la aplicación de criterios de conservación pasiva muy vinculados a la tradición monumentalista. Álvarez Mora lo ha identificado como «modelo defensivo " ${ }^{13}$ y podría ejemplificarse con la política de secteurs sauvegardés francesa pero también con las políticas urbanísticas dominantes sobre los centros históricos en España.

\subsubsection{La nueva cultura de la ciudad: la vía abandonada de conservación «integral» y «activa»}

El eje que estructura el pensamiento urbanístico europeo de los centros históricos en torno a la «nueva cultura de la ciudad» se centra en una redefinición del rol de éstos dentro de la estructura urbano-territorial y en el respeto y recuperación de los valores de la ciudad antigua. Bajo esta perspectiva, el centro histórico debe ser partícipe de la interpretación urbanística de la ciudad en su conjunto, entendido como una pieza más que debe involucrarse en el intento de resolución de los problemas urbanos, entre otros, los de la vivienda y la segregación socio-espacial.

Las estructuras espaciales de los centros históricos se conciben como objeto de salvaguarda y como «recurso» para el reequilibrio social y funcional de la ciudad. De esta manera, en esta perspectiva, se inscriben como intervenciones características, primero, la conservación «integral» y «activa» del patrimonio, es decir, conservación social y física superando la simple «defensa» del monumento; segundo, la descentralización de generadores de «direccionalidad» (centralidad urbana) incompatibles con las construcciones antiguas y, tercero, la dotación de estándares urbanos y residenciales. En este modelo, la vivienda popular adquiere un papel fundamental: no sólo no deberá perder su cabida en los ámbitos históricos, sino que será fomentada como piedra angular de la «recuperación», contrarrestando las tendencias elitizadoras del mercado inmobiliario y optimizando el em-

es una referencia clásica en este tema: CIARDINI, F. y FALINI, P. (eds.), Los centros históricos. Política urbanística y programas de actuación. Barcelona: Gustavo Gili, 1978.

12 CERVELLATI, Pier Luigi. La nuova cultura delle città: la salvaguadia dei centri storici... sviluppo territoriale nell'esperienza di Bologna. Milano: Mondadori, 1977.

13 ÁlVAREZ MORA, A., Conservación del patrimonio... 
pleo de la edificación existente. El centro histórico asume, bajo estos presupuestos, su sentido más originario: el de un espacio físico y social que, sin perder su identidad, contribuye a un desarrollo más equilibrado de la ciudad. El centro histórico se perfila, pues, como parte de las soluciones y no de los problemas de la ciudad contemporánea.

La experiencia de referencia en esta línea de pensamiento urbanístico es, sin lugar a dudas, la iniciada en la ciudad de Bolonia hacia la década de los años 1960, relevante por dos aspectos. En primer lugar, por la doble imbricación entre planeamiento del centro histórico y planeamiento de la ciudad y su territorio, y entre recuperación de la ciudad histórica y política de vivienda social. Así, el objetivo de la recuperación popular del centro histórico se tradujo en la articulación de dos tipos de documentos que afectaban a la ciudad histórica pero -y esto es muy importante - dentro de un planteamiento global de toda la ciudad: el planeamiento urbano general (variantes del Piano Regolatore Generale de 1959, 1970) y los planes de vivienda social (planes de edificación económica y popular de 1963, 1973) ${ }^{14}$.

En segundo lugar, el otro aspecto que confiere relevancia al caso de Bolonia en la década de 1960 es su planeamiento urbanístico, desarrollado con una metodología basada en un rigurosísimo análisis histórico y tipo-morfológico del tejido histórico, cuya influencia ha sido enorme tanto en Italia como fuera de ella.

Leonardo Benevolo, en una entrevista hecha en 2006, valoraba:

«La conservación activa empezó a ponerse por obra en los años sesenta y setenta, y es tal vez la contribución más relevante que hayamos hecho nosotros [los italianos] a la cultura arquitectónica del siglo XX. Considere las intervenciones de Pier Luigi Cervellati en Bolonia, entre 1965 y 1980, que promovieron la restauración de barrios enteros, devolviéndolos a sus habitantes» ${ }^{15}$.

Sin embargo, el modelo de la «nueva cultura de la ciudad», tomado en su integridad, esto es, con su cuestionamiento de la centralidad de la ciudad histórica y su fomento de la vivienda social, ha tenido escasa emulación, incluso dentro de ltalia, y, más aún, si se compara con el éxito que cosechó, por su parte, la metodología de análisis urbanístico con que se instrumentó ${ }^{16}$.

\footnotetext{
${ }^{14}$ CERVELLATI, Ob. Cit, y CERVELLATI, Pier Luigi y SCANNAVINI, Roberto, Bolonia: política y metodología de la restauración de centros históricos. Barcelona: Gustavo Gili, 1976. Una crítica reciente a los resultados en el largo plazo de la experiencia boloñesa se encuentra en: MAREC, Yannick, Villes en crise?: les politiques municipales face aux pathologies urbaines (fin XVIIle-fin XXe siècle). [Paris]: Créaphis, 2007.

15 «La arquitectura se pierde», entrevista...

16 Varias ilustraciones elocuentes de esta influencia se recogen en un mismo libro aunque desde perspectivas diferentemente críticas: BUSQUETS, Joan, «Rehabilitación urbana. Evolución de su contenido teórico e influencia en la práctica urbanística reciente» y FALINI, Paola, «Las nuevas formas del proyecto de «lo existente» en Italia», en VV.AA. La reconstrucción de los centros urbanos. La experiencia europea sobre la rehabilitación de la ciudad histórica. Las Palmas de Gran Canaria: Ayuntamiento de Las Palmas de Gran Canaria, 2002, respectivamente, pp. 25-80 y 81-124.
} 
2.1.2. El modelo defensivo: progresivo dominio de la conservación «pasiva»

Los centros históricos son, según el «modelo defensivo", ámbitos espaciales donde, dada la excepcionalidad de sus valores patrimoniales, las intervenciones normales deben ser la restauración de las piezas arquitectónicas más singulares y la conservación «pasiva» —esto es, tendencialmente museística一 del «ambiente histórico" de calles y plazas. Como el empeño en la restauración de las arquitecturas singulares no reviste las mismas condiciones que la conservación de los elementos de la cultura material urbana (calles, barrios...), lo más frecuente es que la conservación urbanística tenga un marcado carácter escenográfico compatible con la pérdida de la integridad de dicha cultura material. El llamado «fachadismo» ligado a la conservación o protección «ambiental» es la expresión más acabada y extendida - de esta contradictoria deriva.

En este modelo, el cuestionamiento de los usos del espacio y del control de rentas del suelo ( $y$, en consecuencia, de la pervivencia de la vivienda popular en los centros históricos) no tiene lugar, sino más bien lo contrario: las iniciativas de intervención suelen tomar como premisa el mantenimiento de las funciones y tendencias asumidas por la ciudad histórica con la modernidad. De este modo, los centros históricos han ido acumulando cada vez más actividades centrales y el alza de las rentas del suelo se ha traducido en todos los casos en progresiva eliminación de vivienda popular y aumento de la residencia de clases medias y medias-altas.

Francia es posiblemente el país donde esta línea de pensamiento y sus consecuencias prácticas han alcanzado una mayor relevancia. El aislamiento de los centros históricos con vistas a su conservación fue institucionalizado por la Ley Malraux, de 4 de agosto de 1962, que instituyó la figura del secteur sauvegardét7: un conjunto protegido de edificios, espacios públicos y privados que presenta un carácter histórico o estético que justifica su conservación, restauración y valorización. Su creación puede ser propuesta por el municipio o por el Estado, aunque se hace efectiva por orden ministerial (arrêté) con acuerdo del municipio o, en su defecto, del consejo de Estado. Para cada secteur sauvegardé se redacta un Plan de salvaguarda y valorización (PSMV, que sustituye a cualquier otro documento de urbanismo existente sobre el área) y las licencias de obras dentro de su perímetro quedan sometidas al informe favorable del arquitecto de Bâtiments de France (Ministerio de Cultura). EI PSMV incluye plano a escala 1/500 conteniendo los inmuebles que se deben conservar, los que puede obligarse a demoler y los que pueden ser sustituidos, además del reglamento, la exposición de motivos, anexos de servidumbres y fichas por edificios (descripción e intervenciones necesarias). Las disposiciones del PSMV se aplican sobre partes exteriores e interiores de los

17 El principal decreto de aplicación es de 13 de julio de 1963. 
inmuebles y sobre los espacios libres y comprenden todas las disposiciones de un plan de ordenación urbanística más otras disposiciones en materia de protección, obligación de demolición o de modificación ${ }^{18}$.

Los secteurs sauvegardés expresan con total nitidez la consideración de la excepcionalidad urbana ligada al carácter histórico y monumental, que se lleva al punto de interferir con las competencias urbanísticas habituales de las colectividades territoriales. Los primeros PSMV estaban a menudo reducidos a una visión monumental o pintoresca. Aislaban un área con un perfil histórico incuestionable para acometer su «defensa» y conservación pasiva, podríamos decir, «petrificante» (en el doble sentido de la palabra: sobre las piedras y buscando su inmutabilidad). Su evolución ha ido integrando la dimensión urbana y, sobre todo, las necesidades del espacio residencial pero, sin embargo, es convencionalmente aceptado que, si bien los secteurs sauvegardés han cumplido sus objetivos de salvaguarda en relación con los edificios, su efecto ha sido exactamente inverso en relación con los grupos sociales que los habitaban. Los espacios históricos defendidos se están convirtiendo en espacios sociales exclusivos y «terciarizados» ${ }^{19}$.

De hecho, en general, este modelo defensivo, dominante en Francia como en toda Europa, ha venido a reforzar la interpretación de los centros históricos como recursos turísticos. Esta tendencia ha sido tan marcada y poderosa que podría decirse que muchos de los más afamados conjuntos declarados en Europa están convertidos hoy en una suerte de parques temáticos de sí mismos.

\section{EL DESARROLLO DEL MODELO DEFENSIVO EN LAS POLÍTICAS DE CENTROS HISTÓRICOS EN ESPAÑA. EL ROL ASIGNADO A LA ARQUITECTURA CONTEMPORÁNEA}

En ninguno de los dos modelos que hemos presentado brevemente, centrados en opciones de conservación «activa» —en la perspectiva global de la nueva cultura de la ciudad - o «pasiva» — limitada a la protección de ámbitos seleccionados_-, la arquitectura contemporánea parece tener un lugar específico más allá de sus modalidades de restauración o rehabilitación, es decir, con un carácter claramente subalterno del objetivo de conservación de los edificios patrimoniales. Sin embargo, como es fácil de percibir paseando por los centros históricos de Europa y sobre todo de España, pese a la hegemonía del «modelo defensivo» y de los criterios de conservación dominantes desde hace más de medio siglo, la arquitectu-

18 MERLIN, Pierre y CHOAY, Françoise, Dictionnaire de l'urbanisme et de l'aménagement. Paris: Presses Universitaires de France, 2005 (1ํed.: 1988).

19 GAUDRIC, Paul, «Secteurs sauvegardés», informe elaborado en el marco del documento Integrated Urban Regeneration in the European Union, preparatorio del Toledo Informal Ministerial Meeting on Urban Development de junio de 2010, pp. 722-730.

http://www.vivienda.es/es/jornadas/TOLEDO/ANNEXES\%20TO\%20THE\%20SURVEY\%20vs\%20English.pdf (Consultado: 18 de octubre de 2010). 
ra contemporánea ha alcanzado una presencia importante. ¿Cómo puede entenderse esta aparente paradoja? Apuntaremos algunas notas que podrían orientar o servir para argumentar alguna respuesta a esta pregunta sirviéndonos del estudio de documentos jurídicos fundamentales en el diseño de las políticas públicas de urbanismo y patrimonio, y de la experiencia de algunas ciudades históricas de Castilla y León.

Nuestra hipótesis básica es que los presupuestos de la conservación monumental en España —originarios de las políticas patrimoniales- se extendieron a las políticas urbanísticas y esto propició importantes transformaciones en las ciudades históricas. Desde mediados del siglo XX, estas transformaciones se habrían expresado mayoritariamente, en lo que al espacio se refiere, bajo la forma de construcción de edificios de lenguaje arquitectónico contemporáneo. La presencia de estas arquitecturas en tejidos históricos habría dependido, en cada caso, de diversos factores, entre los que destacan el contexto cultural institucionalizado en el marco jurídico de aplicación y la coyuntura económica-inmobiliaria. No obstante, y siempre de manera tentativa, podría perfilarse una evolución general con un primer momento en que esa presencia está marcada por lo cuantitativo —una cierta proliferación de las arquitecturas contemporáneas en los ámbitos históricos no catalogados - y con un segundo momento (reacción al primero, al menos en parte, y que llega hasta la actualidad) en que esa presencia tiene un perfil más cualitativo o, como veremos, más cualificador: los lenguajes claramente contemporáneos se aplican de manera más puntual y seleccionada, con cabida incluso en las áreas protegidas.

\subsection{El patrimonio urbano como patrimonio edificado monumental. Políticas patrimoniales y políticas urbanísticas en España e intervenciones edificatorias hasta 1975}

En España, aun a pesar de la clara influencia de la urbanística italiana de la segunda mitad del siglo XX, las políticas aplicadas a los centros históricos se han alineado generalmente con el «modelo defensivo». Esta filiación ha venido inducida en buena medida por los criterios impuestos desde el marco normativo del patrimonio sobre la legislación urbanística ${ }^{20}$.

Durante la primera mitad del siglo XX, cuando la urbanística española aun se encontraba enmarcada entre la reforma urbana (aperturas viarias) y el ensanche, dos textos legislativos, el Decreto Ley de 9 de agosto de 1926, del Tesoro Artístico Arqueológico Nacional, y la Ley de 13 de mayo de 1933, de Patrimonio

20 ÁLVAREZ MORA, Alfonso, "Los centros históricos en Castilla y León», en RIVAS, Juan Luis de las (coord.), Atlas de Conjuntos Históricos de Castilla y León. [Valladolid], Consejería de Cultura y Turismo, [2009], pp. 39-58. 
Artístico, vendrán a anunciar e instaurar, respectivamente, la figura del «conjunto histórico-artístico» como patrimonio urbano institucionalizado.

Para la norma de 1926, el Tesoro Artístico Arqueológico Nacional comprendía «...el conjunto de muebles e inmuebles dignos de ser conservados para la nación por razones de Arte y Cultura», incluidas «las edificaciones o conjuntos de ellas, sitios y lugares de reconocida y peculiar belleza, cuya protección y conservación sea necesaria para mantener el aspecto típico, artístico y pintoresco, característico de España».

La ley de 1933 señalaba, precisamente, que el patrimonio histórico-artístico nacional estaba formado por

«cuantos inmuebles y objetos muebles de interés artístico arqueológico, paleontológico o histórico haya en España de antigüedad no menor a un siglo; también aquellos que, sin esta antigüedad, tengan un valor artístico o histórico indiscutible, exceptuando, naturalmente, las obras de autores contemporáneos».

Esa misma ley establecía que podrían formar parte del catálogo de Monumentos Histórico-Artísticos

"los conjuntos urbanos y los parajes pintorescos que deban ser preservados de destrucciones o reformas perjudiciales». Con ello, las prescripciones referentes a la defensa, conservación y acrecentamiento de los monumentos serían también aplicables a «los conjuntos urbanos y rústicos (...) calles, plazas, rincones, barrios, murallas, fortalezas, ruinas fuera de las poblaciones que por su belleza, importancia monumental o recuerdos históricos puedan declararse incluidos en la categoría de rincón, plaza, calle, barrio o conjunto histórico-artístico».

Así pues, la primera regulación de la intervención sobre el patrimonio urbanístico se identificó con la perspectiva conservacionista aplicada a los monumentos que, centrándose en la pervivencia física de los vestigios del pasado, obviaba los contextos sociales y económicos en los que están involucrados y sus efectos sobre los mismos. De esta manera,

"Las personas que habitan esos espacios, la economía que los sostiene, su indiscutible pertenencia a la ciudad en la que se integran y a la que se deben, todo lo que tenga que ver con su condición de realidades urbanas ha sido conscientemente soslayado en el marco de la valoración emprendida. El énfasis (...) se pone en aquellos otros aspectos que resaltan su realidad física, interesando de estos "conjuntos" lo que la historia había dejado, como huella, en las piedras más emblemáticas, en los edificios, en suma, más comprometidos con el poder que los ha asistido a lo largo de su conformación como centros urbanos»²1.

Las primeras declaraciones patrimoniales de conjuntos urbanos se hicieron con criterios poco coherentes: no alcanzaron a todas las ciudades históricas sino sólo

${ }^{21}$ ÁLVAREZ MORA, Alfonso, «Los centros históricos...», p. 39. 
a las más relevantes y, dentro de ellas, con frecuencia, sólo a las áreas más singulares. Por otra parte, esta voluntarista defensa pasiva de los bienes patrimoniales chocaba en la realidad con las enormes limitaciones (empezando por las financieras) de las políticas de conservación, así que su eficacia frente al deterioro y abandono de los mismos fue más que escasa ${ }^{22}$.

En el año 1956, la aprobación de la primera ley del suelo puso los cimientos de los que han sido hasta hoy los instrumentos fundamentales de planificación urbana en España, entre ellos el Plan general de ordenación urbana (PGOU) y los planes y proyectos de reforma interior, orientados a la intervención «correctiva» en la ciudad consolidada y antecesores de las figuras de planeamiento que, en el futuro, se aplicarían sistemáticamente a los centros históricos ${ }^{23}$.

Los años siguientes, desde finales de la década de 1950 hasta 1975, las ciudades españolas económicamente más dinámicas se vieron inmersas en un doble proceso: de un lado, la redacción de planes generales conforme a la nueva ley y, de otro lado, una enorme alza en la producción de vivienda.

La arquitectura contemporánea había tenido, hasta esas fechas, presencia mínima en los tejidos históricos de ciudades españolas. Sería a partir de la década de 1960 cuando, en muchos casos, las sustituciones del caserío tradicional, animadas por el ciclo inmobiliario alcista y por los frecuentes aumentos de volumen edificado posibilitados por los planes de ordenación vigentes, darían lugar a una «eclosión» de arquitectura contemporánea en muchas áreas urbanas históricas atractivas para la inversión inmobiliaria y que no habían sido declaradas conjunto histórico-artístico.

La observación actual de las ciudades históricas españolas permite conjeturar que esta interpretación es más probable en el caso de ciudades que, teniendo en aquel momento saldos demográficos positivos y economías en alza, no disponían de suelo urbanizado fuera de la ciudad histórica que permitiese canalizar la demanda creciente, siquiera la más solvente. Las sustituciones habrían venido pautadas por la expectativa de obtención de renta por aumento del volumen edificado en unas áreas - las históricas- a priori más equipadas y, por tanto, en general, con más calidad urbana que la mayor parte de las periferias urbanas nacientes. Esto, además, podría haber puesto las bases de una incipiente segregación social al alza de las áreas históricas más revalorizadas frente al resto de la ciudad.

Desde el punto de vista formal, las sustituciones en los tejidos históricos tendrán a menudo un gran impacto. No sólo introdujeron un cambio tipológico y de lenguaje arquitectónico sino que, con frecuencia, dando realización a los planes funcionalistas característicos del desarrollismo, también se acompañaron de re-

22 Idem.

23 TERÁN, Fernando de, Planeamiento urbano en la España contemporánea (1900-1980). Madrid: Alianza, 1982. Del mismo autor también: Historia del urbanismo en España. III, Siglos XIX y XX. Madrid: Cátedra, 1999. 
tranqueos y aumentos de altura y de una clara tendencia a la simplificación y homogeneización de los usos del suelo. Por yuxtaposición de sustituciones de gran impacto, algunas calles llegaron a perder toda referencia de su condición histórica a excepción de su traza viaria. Valladolid sería, entre las ciudades de Castilla y León, el ejemplo palmario de este fenómeno ${ }^{24}$ (Figuras 1 y 2), al que no se sustrajeron tampoco otras, como Salamanca o Zamora.

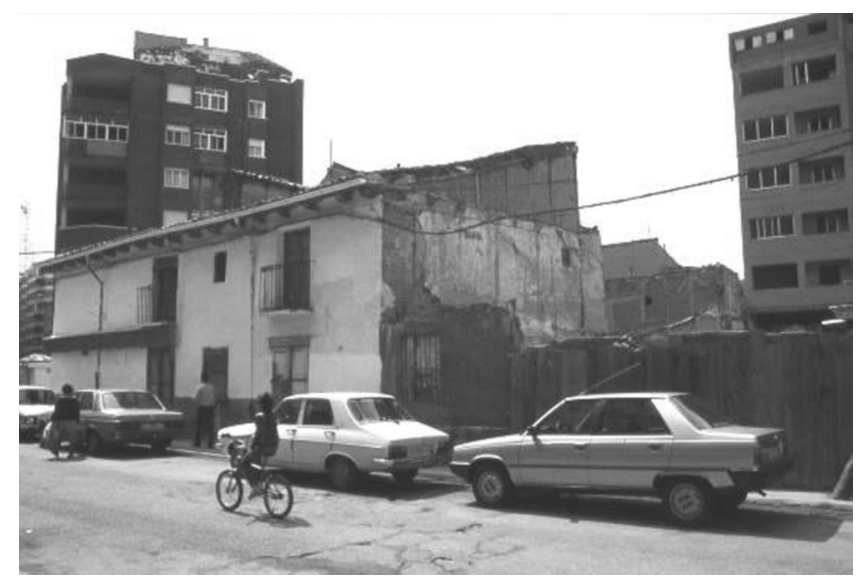

Figura 1. Valladolid. Vista del tramo central de la calle Imperial, aledaña a la Plaza de San Pablo, hacia 1975 (Foto: archivo del Instituto universitario de urbanística de la Universidad de Valladolid).

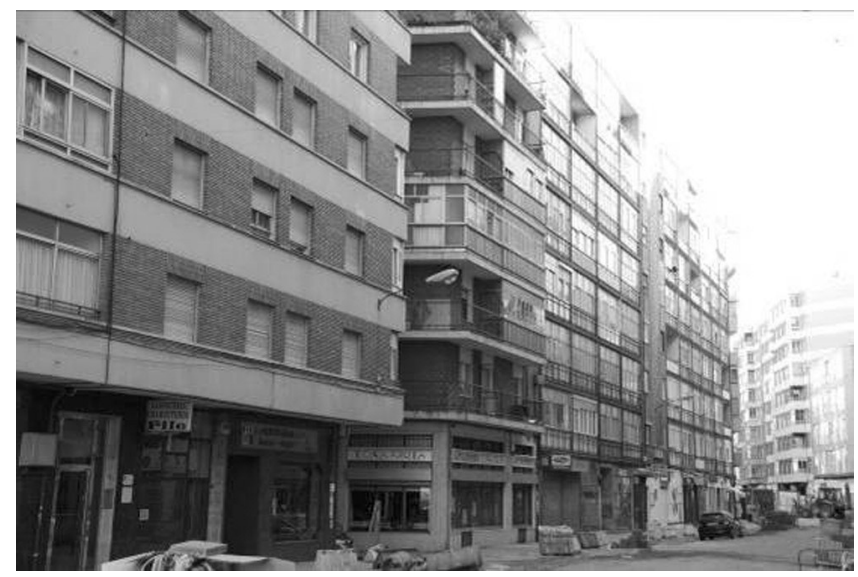

Figura 2. Valladolid. Tramo central de la calle Imperial en 2008.

24 A propósito del centro histórico de Valladolid es imprescindible ALVAREZ MORA, Alfonso, El mito del centro histórico. Puebla: Universidad Iberoamericana Puebla, 2006.

25 HERNÁNDEZ LEÓN, Juan Miguel y LLIMARGAS I CASAS, Marc, Arquitectura española contemporánea: la otra modernidad. Barcelona: Lunwerg, 2007, pp. 18-26. 
Y, si bien es cierto que la calidad media de esta arquitectura que eclosionó en las ciudades históricas entre 1955 y 1975 fue más bien mediocre (Figura 3), no faltaron tampoco ejemplos interesantes muy altamente valorados por la crítica como contribuciones a la «recuperación de la modernidad española» 25 , caso de las obras de Alejandro de la Sota, arquitecto fundamental en la arquitectura española contemporánea, construidas en Zamora (edificio Olmedo, 1956, sobre los terrenos del convento de Santa Clara demolido en 1949) (Figura 4) y, sobre todo, en Salamanca, donde las viviendas de la C/ Prior (1965) (Figura 5), en las inmediaciones de la Plaza Mayor, han sido reconocidas como «su edificio más celebrado» en la región ${ }^{26}$. También se puede citar como ejemplo el instituto de enseñanza media «Nuñez de Arce», proyecto del arquitecto Miguel Fisac, levantado en Valladolid en 1961, en las inmediaciones de las ruinas de los conventos de San Benito y San Agustín.

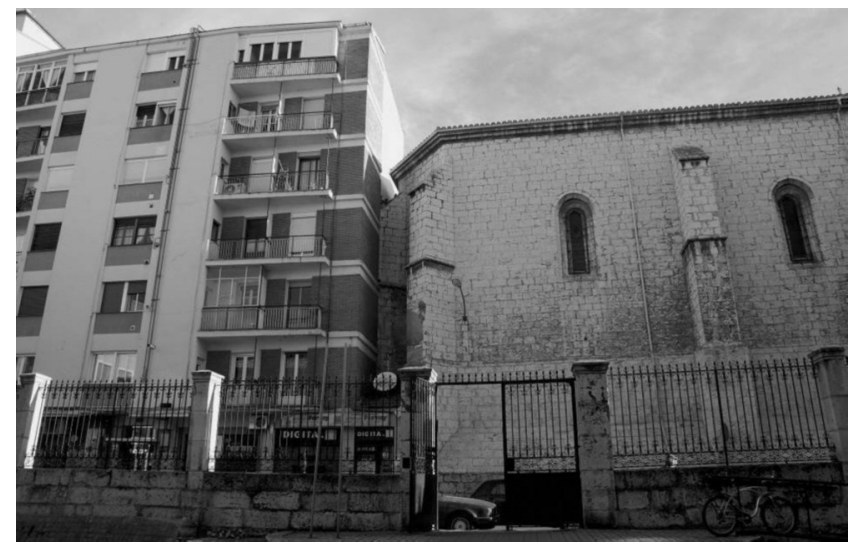

Figura 3. Ejemplo de la mala calidad arquitectónica de las intervenciones de las décadas de 1960 y 1970 en áreas históricas. Imagen actual del entorno del convento de la Concepción, en Valladolid.

26 NIETO GONZALEZ, José Ramón (coord.), Patrimonio arquitectónico de Castilla y León. Vol. VI. Valladolid: junta de Castilla y León, 2007, p. 115. 


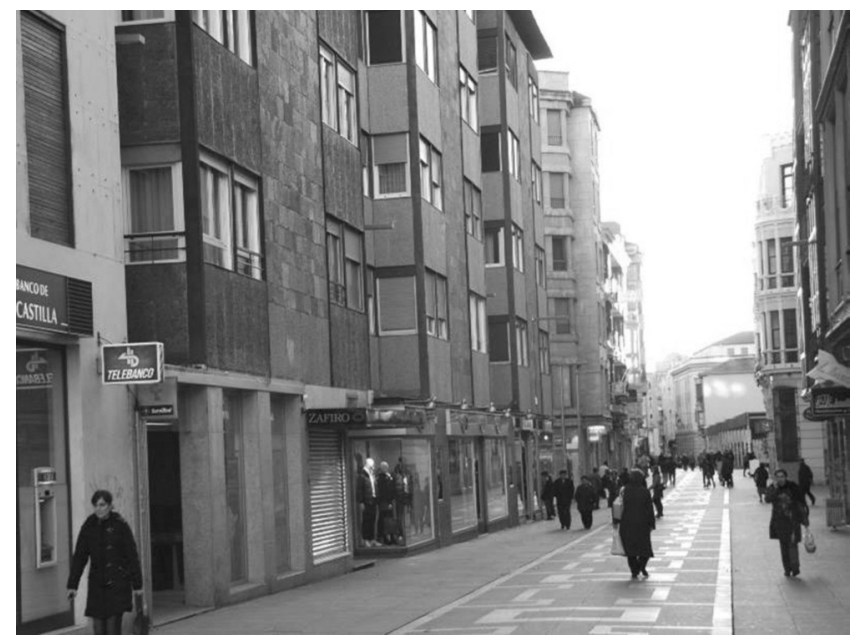

Figura 4. Edificio Olmedo (1956), en la calle de Santa Clara (Zamora), proyecto de Alejandro de la Sota.

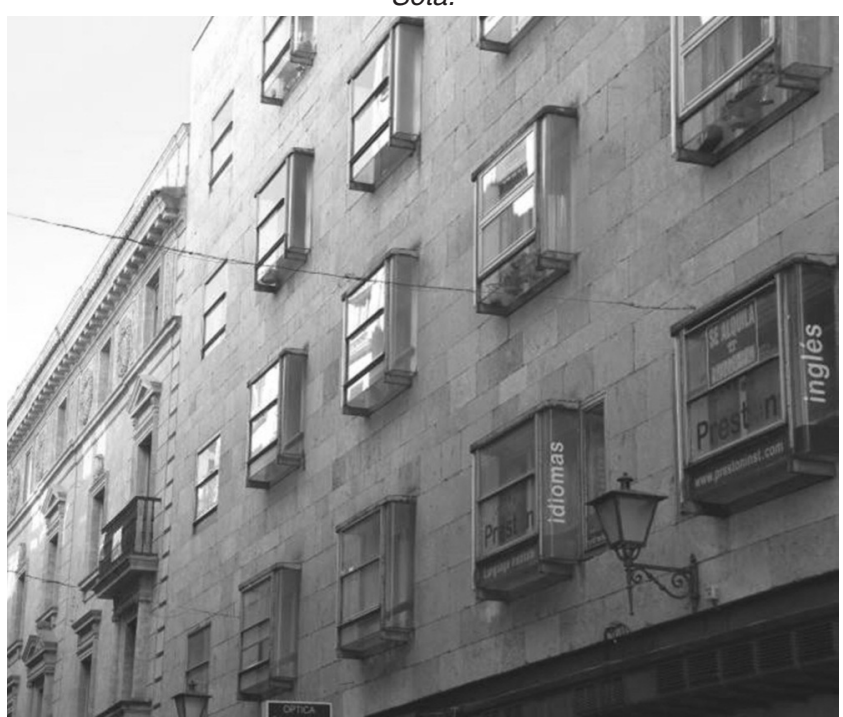

Figura 5. Viviendas en la calle Prior de Salamanca, en las inmediaciones de la Plaza Mayor, obra de Alejandro de la Sota (1965).

Desde el punto de vista funcional, las sustituciones ahondarán en el carácter central de algunas áreas históricas no catalogadas que venían cubriendo funciones de centralidad en la ciudad deI XIX. Pero también se produjeron sustituciones en muchas áreas históricas de carácter popular y, en este sentido, aunque se produ-

27 ALVAREZ MORA, Alfonso, Conservación del patrimonio... 
jese de todos modos un cambio efectivo de población, podría no haber sido infrecuente que, al menos una fracción de las nuevas viviendas edificadas sobre trazas antiguas, estuviese acogida a la protección oficial, esto es, orientada a estratos socioeconómicos medio-bajos. El caso de Valladolid, ciudad con una extensa y muy sustituida ciudad histórica, provee no pocos ejemplos de ello en barrios como el de San Nicolás, el arrabal de La Victoria u otros (Figura 6).

Con el crecimiento generalizado de las primeras grandes periferias obreras españolas, el espacio urbano se segregará progresivamente y la tendencia dominante sobre el centro histórico será la expulsión de la vivienda de las clases más bajas y el refuerzo de las actividades direccionales y de comercio no cotidiano, es decir, en definitiva, la progresiva destrucción del sustrato social y económico (talleres, artesanos, pequeño comercio cotidiano...) que daba sentido a las formas edificadas $^{27}$. La defensa de las áreas catalogadas como históricas es, en este proceso, complementaria a la destrucción de aquéllas que no habían sido reconocidas como tales. Como dice Álvarez Mora:

"La conservación del patrimonio y la transformación-destrucción de la ciudad tradicional no sólo no se contradicen sino que se complementan con toda claridad»28.

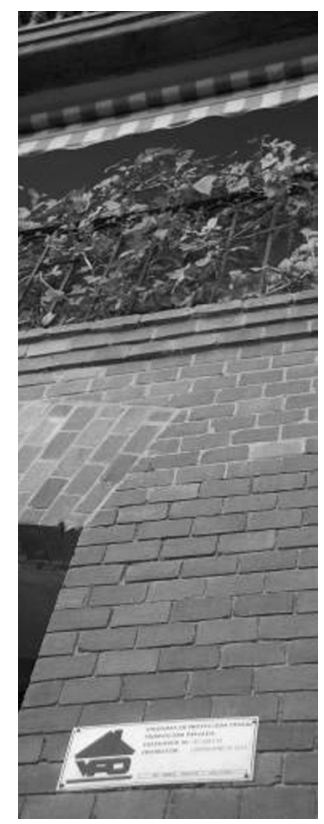

Figura 6. Probablemente, una de las últimas edificaciones de VPO promovidas en el tejido histórico de Valladolid (Plaza del Coso).

28 Idem,. p. 7.

29 ALVAREZ MORA, Alfonso, Conservación del patrimonio... 
En definitiva, en el periodo tardofranquista, podría interpretarse la emergencia de una nueva definición del proceso de conservación/destrucción que había caracterizado desde sus orígenes las intervenciones de la urbanística moderna sobre la ciudad histórica ${ }^{29}$. En este caso, la cultura conservacionista que inspira los dispositivos normativos jugará un papel esencial. La legislación patrimonial catalogará áreas urbanas que quedarán preservadas de las sustituciones (que no de la ruina) y la política urbanística, en el contexto de un alza inmobiliaria hasta entonces sin precedentes, propiciará la transformación de la ciudad histórica no catalogada, transformación que, con mucha frecuencia, se expresaría con el lenguaje de la arquitectura contemporánea (Figura 7).

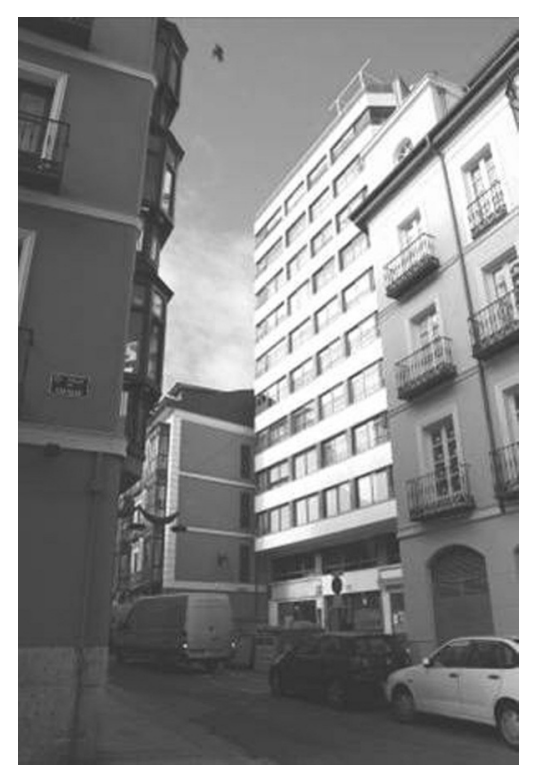

Figura 7. Ejemplo de la brutalidad de la expresión de la arquitectura contemporánea en las sustituciones efectuadas hacia las décadas de 1960 y 1970 en algunos cascos históricos (calle Regalado, Valladolid).

En general, el proceso de conservación/destrucción así definido podría haber afectado con intensidad variable (dependiente, probablemente, de los procesos urbanísticos habidos fuera de la ciudad histórica) a una parte de las ciudades españolas dotadas de un cierto dinamismo. Y lo haría hasta mediados de los años 1970, es decir, hasta el cierre de un ciclo de crecimiento urbano desbocado en España que, desgraciadamente, no sería el último ni el más grave. En ese momento, la reestructuración económica mundial y el cambio político en España se unirán a otros factores como la creciente presión social contra la aniquilación del patrimonio edificado y la influencia ideológica de la «nueva cultura de la ciudad» para, en el marco de un mercado inmobiliario en crisis, hacer efectiva una revisión de los cri- 
terios patrimoniales y urbanísticos dominantes que comenzará a materializarse, aproximadamente, a partir de la década de 1980.

\subsection{Marco jurídico y nuevos mecanismos del proceso de conservación/destrucción de la ciudad histórica en España en el cambio de siglo}

La ley del suelo será reformada en 1975 y su reglamento de planeamiento se promulgará en 1978. Se redefinirán entonces los planes de reforma interior y, entre sus finalidades, se contemplarán la «protección del medio urbano para su conservación y mejora en determinados lugares» y la «ordenación de recintos y conjuntos arquitectónicos, históricos y artísticos».

Bajo este nuevo marco legislativo, en el momento de la transición política, España asistirá al surgimiento de una nueva generación de planes generales redactados en un incipiente marco democrático. Ese nuevo planeamiento se reorientará mayoritariamente a la «recuperación» de la ciudad — divisa de éxito del PGOU de Madrid de 1985 - y se articulará, como veremos, con el surgimiento de una nueva generación de planes especiales de protección de áreas históricas ${ }^{30}$.

En 1985, se promulgó la Ley 16/1985, de patrimonio histórico español. Su entrada en vigor no supuso precisamente un nuevo entendimiento de la conservación como «una alianza necesaria entre la herencia expresada físicamente en las piedras seculares y lo que proporciona sentido histórico a dicha "física" (...) un proceso amplio de producción social»»1. Por el contrario, el patrimonio histórico español, según la ley de 1985, se seguirá definiendo por el interés artístico, histórico, paleontológico o arqueológico, a los que se añaden entonces el etnográfico, científico, técnico y antropológico. La ley de 1985 definirá, además, como «conjunto histórico»:

«la agrupación de bienes inmuebles que forman una unidad de asentamiento, continua o dispersa, condicionada por una estructura física representativa de la evolución de la comunidad humana, por ser testimonio de su cultura o constituir un valor de uso y disfrute de la colectividad. Asimismo, es conjunto histórico cualquier núcleo individualizado de inmuebles comprendidos en una unidad superior de población que reúna esas mismas condiciones y pueda ser claramente delimitado».

La novedad más trascendente incorporada por la ley de 1985 es la institucionalización de un vínculo formal entre la política patrimonial y la urbanística. En adelante, será obligatoria la redacción de Planes Especiales para los conjuntos históricos $(\mathrm{PECH})$. Sin embargo, los cometidos encomendados a estos documentos no son estrictamente de ordenación urbanística —como preveía la legislación ur-

30 AA. VV. 10 años de planeamiento urbanístico en España: 1979-1989. Madrid: Ministerio de Obras Públicas y Urbanismo, 1990.

31 ÁlVAREZ MORA, A., «Los centros históricos...», p. 42. 
banística para los PERI — sino que se orientarán a la conservación, reafirmando la pervivencia de la petrificante perspectiva «pasiva»:

«En los instrumentos de planeamiento relativos a conjuntos históricos se realizará la catalogación, según lo dispuesto en la legislación urbanística, de los elementos unitarios que conforman el conjunto, tanto inmuebles edificados como espacios libres exteriores o interiores (...) A los elementos singulares se les dispensará una protección integral. Para el resto de los elementos se fijará, en cada caso, un nivel adecuado de protección (...) Excepcionalmente, el Plan de protección de un conjunto histórico podrá permitir remodelaciones urbanas, pero solo en caso de que impliquen una mejora de sus relaciones con el entorno territorial o urbano o eviten los usos degradantes para el propio conjunto (...) La conservación de los conjuntos históricos declarados bienes de interés cultural comporta el mantenimiento de las estructura urbana y arquitectónica, así como de las características generales de su ambiente. Se considerarán excepcionales las sustituciones de inmuebles, aunque sean parciales, y sólo podrán realizarse en la medida en que contribuya a la conservación general de carácter del conjunto».

Una cierta influencia de la «nueva cultura de la ciudad» se deja sentir en la ley cuando refiere que los PECH podrían incluir la previsión de Áreas de Rehabilitación Integrada (ARI) que «permitan la recuperación residencial y de las actividades económicas» dentro de ámbitos delimitados. En estas áreas, previa delimitación, se financiarán obras de rehabilitación edificatoria y reurbanización de espacios públicos.

Este nuevo instrumento, las ARI, parecía brindar la oportunidad de contener, vía gestión urbana, las amenazas de «terciarización» y «elitización» que ya se hacían sentir sobre las áreas históricas aun poco afectadas por sustituciones. Sin embargo, si tomamos como referencia la política específica desarrollada por la Comunidad Autónoma de Castilla y León, podría conjeturarse que su desarrollo no ha supuesto un cambio sustancial en la evolución de los centros históricos, ni en términos edificatorios ni funcionales ${ }^{32}$. Un dato puede ser ilustrativo: hasta 2010, las viviendas afectadas por ARIs en centros históricos y en áreas históricas declaradas de la región alcanzan un total de 5.773 viviendas. Para tener una noción muy somera del significado de esta cantidad, podemos prorratearla sobre el total de los conjuntos históricos castellanos y leoneses declarados hasta la misma fecha (140) y obtendríamos la limitada cantidad de 40 viviendas por conjunto ${ }^{33}$. Con estas cifras a la vista no puede valorarse que haya habido una influencia real y efectiva del modelo de la «nueva cultura de la ciudad».

32 Los resultados de investigaciones específicas en otras comunidades autónomas, concretamente de la valenciana, apuntan también a que la rehabilitación residencial es la «gran asignatura pendiente»: GAJA I DÍAZ, Fernando, Intervenciones en centros históricos de la Comunidad Valenciana. Valencia: Conselleria d'Obres Públiques, Urbanisme i Transport y Colegio Oficial de Arquitectos de la Comunidad Valenciana, 2001, p. 227.

33 «Políticas urbanas aplicadas a los conjuntos históricos: logros y fracasos. Hacia una propuesta de rehabilitación urbana como alternativa al modelo inmobiliario extensivo», proyecto de investigación desarrollado en el Instituto Universitario de Urbanística de la Universidad de Valladolid en el periodo 2010-2012, financiado por el Ministerio de Educación y Ciencia, Plan Nacional de I+D+i (Ref.: CSO201015228), y dirigido por Alfonso Álvarez Mora. 
La ley de patrimonio de 1985 también redefinirá la capacidad de decisión de las comisiones de patrimonio estableciendo que, con la aprobación definitiva del $\mathrm{PECH}$, los Ayuntamientos tendrán plenas competencias sobre las licencias de obra en el centro histórico, exceptuando los bienes de interés cultural —los monumentos-, los jardines históricos y sus entornos. En la práctica, esto significará que las decisiones referentes a las sustituciones y rehabilitaciones en los recintos de reconocido valor histórico quedarán sometidas a la normativa del plan y no al criterio de la comisión encargada de la tutela de los bienes patrimoniales.

Con posterioridad a 1985, el marco legislativo estatal ha tenido importantes variaciones, en particular, las vinculadas a la descentralización de competencias en materia de urbanismo y patrimonio. Sin embargo, estos cambios parecen no haber afectado a los elementos básicos del esbozo aquí propuesto:

- la hegemonía del «modelo defensivo» en las políticas patrimoniales, en particular, las del patrimonio urbano; y

- la primacía de los criterios de excepcionalidad y conservación pasiva en la gestión de los centros y las ciudades históricas, criterios proyectados desde la esfera de la legislación patrimonial sobre la legislación urbanística, que los ha asumido con pocos matices y sin complementarlos con criterios de ordenación urbana efectiva.

Un reciente trabajo de investigación dirigido por Álvarez Mora ${ }^{34}$ sobre una muestra de un centenar de casos de todas las comunidades autónomas de España ha arrojado como resultado una tipificación de la evolución en el periodo 1950-2005 de los municipios de España con centros históricos declarados. Según ésta:

«La gran mayoría de los núcleos que contienen un conjunto histórico declarado como Bien de Interés Cultural, se localizan en comunidades en las que dominan los «núcleos poco dinámicos» o en clara recesión, que son, a su vez, entidades municipales que están respondiendo a la dinámica que se deriva de una situación semejante, en consonancia, por tanto, con un territorio identificado con categorías de marginación económica y social»»35.

Es preciso insistir en lo anterior porque las notas que se perfilan de aquí en adelante no pretenden ser generalizables al heterogéneo universo de los centros históricos, sino sólo a los que muestran un mayor dinamismo urbano, es decir, cuantitativamente, una minoría. En ellos, si bien la catalogación del patrimonio urbano puede haberse desvinculado de su ruina, no resulta evidente, como veremos, que le haya sustraído a la piqueta y, menos aun, al cambio social («elitización»), que parece haber encontrado campo abonado tanto en las operaciones de sustitución (parcial o total) como en las de rehabilitación.

34 «Producción de la vivienda y recuperación residencial...».

35 ÁLVAREZ MORA, Alfonso, «La vivienda como indicador de la recuperación de los conjuntos históricos", en RIVAS SANZ, Juan Luis de las y RODRÍGUEZ MARTíN, Cristina (coords.), Ciudad sobre ciudad: interferencias entre pasado y presente urbano en Europa: Simposio internacional. Valladolid: Fundación del Patrimonio Histórico de Castilla y León, 2009. 
Durante las décadas de 1950 a 1980, la presencia de la arquitectura contemporánea en algunas ciudades históricas españolas se multiplicó como parte del proceso de destrucción de partes no catalogadas de las mismas. Pero, a partir de mediados de la década de 1980, el rol asignado a esa arquitectura por las políticas urbanísticas aplicadas a la ciudad histórica se modificó, coincidiendo con un nuevo ciclo alcista, con la consolidación de una cierta cultura democrática y el aumento de la demanda de consumo simbólico y cultural de masas, con la redefinición de competencias de los Ayuntamientos sobre los centros históricos y con la vigencia de los instrumentos de planeamiento de nueva generación.

Los mecanismos del proceso de conservación/destrucción se redefinieron. Los criterios conservacionistas se desarrollaron largamente, a partir de la década de 1980, en la lógica de la «conservación ambiental» con que, a menudo, se afectó a buena parte de la edificación antigua superviviente de la oleada de sustituciones de las décadas de 1960 y 1970 y esto se perfila como un factor importante en la reorientación de las transformaciones acaecidas en los centros históricos «protegidos».

Cuando, en la década de 1990, el mercado inmobiliario se reactivó como nunca lo había hecho antes en la historia de España, también sacudió —como no podía ser menos- al centro histórico de la ciudad. A falta de estudios específicos, sólo a partir de la observación directa informal, puede conjeturarse que la coyuntura inmobiliaria propició una nueva oleada de derribos que afectó a buena parte de la edificación antigua no catalogada y también a la catalogada, pero dentro de los límites de transformación (a menudo muy laxos) establecidos por el planeamiento. En el caso de las abundantes arquitecturas residenciales heredadas que habían sido protegidas por una catalogación de tipo ambiental o similar, esto supondría la posibilidad del derribo y sustitución con la sola condición de la preservación (en ocasiones, incluso, sólo la reproducción «idéntica») de la fachada.

Por ejemplo, en Castilla y León, en julio de 2007, se contabilizaban 85 conjuntos históricos declarados, 121 si consideramos los $\mathrm{CH}$ cuyo expediente estába en tramitación, y había tres ciudades, Ávila, Salamanca y Segovia, que contaban con sitios incorporados por la UNESCO al Patrimonio de la Humanidad. Sin embargo, pese a la diligencia de la política autonómica en relación con la protección patrimonial, los Planes Especiales vigentes afectando conjuntos históricos apenas sobrepasaban la treintena: ocho PERI y $26 \mathrm{PECH}$, de los que nueve correspondían a las ciudades capitales de provincia ${ }^{36}$. Dentro de esta treintena, la protección «ambiental» de la edificación residencial era la tónica dominante. Esta tendencia parece confirmarse en 2010 , cuando el número de conjuntos declarados alcanza los 140, mientras los Planes Especiales sólo llegan a $38^{37}$.

36 VÁZQUEZ, Gregorio, «Herramientas urbanísticas de protección del patrimonio en los centros históricos de Castilla y León» en RIVAS (coord.), Atlas..., p. 59.

37 «Políticas urbanas aplicadas a los conjuntos históricos...» 
La filosofía conservacionista-monumentalista que recorre los $\mathrm{PECH}$ no ha impedido las demoliciones habidas desde 1990 en esas ciudades históricas, aunque sí habría determinado que las sustituciones de edificios sin protección o con protección ambiental (enmascaradas o no como «rehabilitaciones») comportaran, en general, un menor impacto sobre la escena urbana que las sustituciones ejecutadas en el ciclo alcista precedente, bien sea por la conservación o reproducción de las fachadas, bien por la normativa de composición de las mismas, la limitación de las alturas y la conservación de las alineaciones (Figuras 8,9 y 10). Sin embargo, en ausencia de una política de vivienda social específica, el impacto de estos cambios en términos de segregación social fue probablemente aun más acentuado que en épocas precedentes. Los cambios se produjeron sobre áreas que ya habían cobrado una importante valoración social debida, al menos en parte, al auge de la cultura patrimonialista y a las modificaciones que ésta indujo sobre la gestión de las ciudades. Las condiciones parecían dadas para la progresiva conversión de las ciudades históricas en áreas de residencia exclusiva.

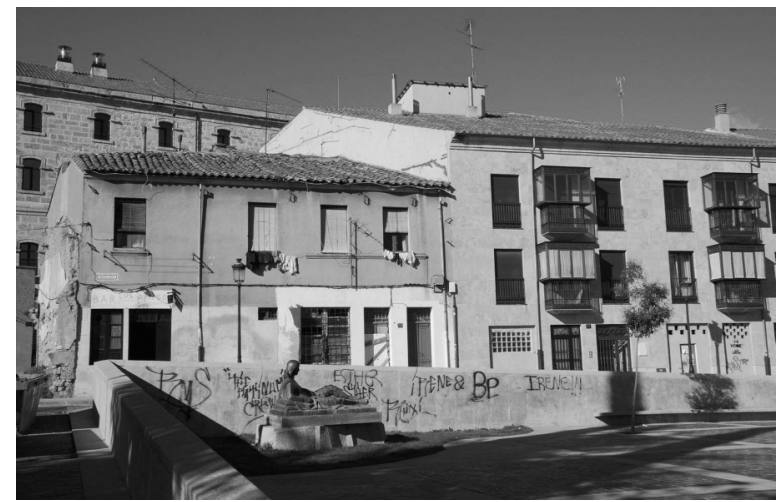

Figura 8. Ejemplo de caserío tradicional y sustitución reciente en Salamanca.

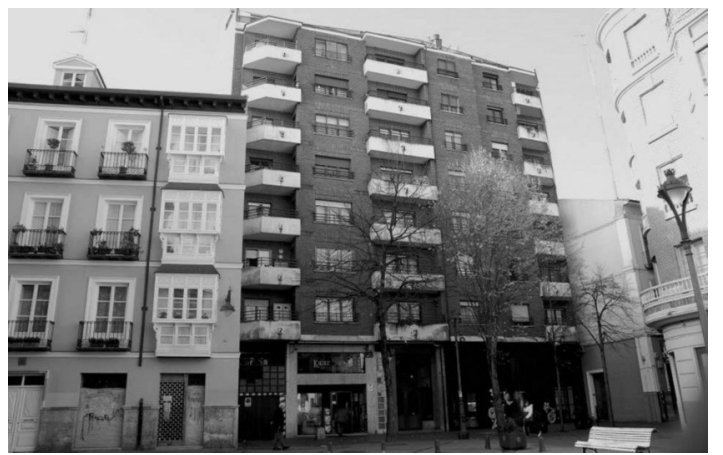

Figura 9. Dos generaciones de sustituciones en el casco histórico de Valladolid (Plaza del Salvador): a la izquierda, la más reciente, conserva la fachada. A la derecha, un ejemplo típico de sustitución con retranqueo y elevación de alturas y volumen edificado de los años 1960-1970. 


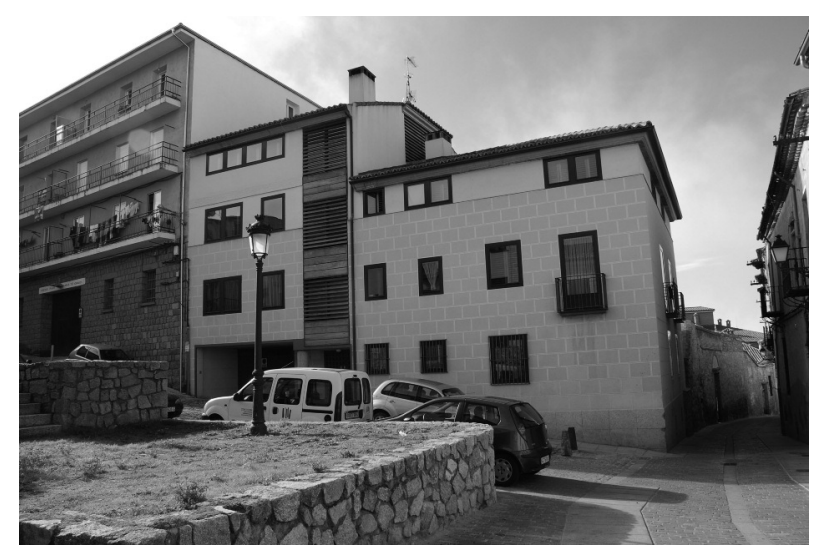

Fig. 10. Dos ejemplos más de generaciones de sustituciones, en este caso, dentro del recinto amurallado de Ávila (Plaza del horno del conde).

Desde la década de 1980, las sustituciones no dejaron de producirse sobre las ciudades históricas pero la generalización del criterio de conservación de la «escena urbana» implícito en la protección ambiental las sustrajo de la expresividad de la arquitectura contemporánea y las volvió poco perceptibles para ojos inexpertos (Figuras 11 y 12). No obstante esta «invisibilidad», las nuevas modalidades de sustitución no contradicen, sino que más bien podrían haber reforzado con el marchamo de una historicidad ahora cotizada, la tendencia a la segregación socio-espacial «hacia arriba» de los centros históricos y, en general, en virtud del acrecentamiento de las patrimonializaciones más o menos formales también, de otros ámbitos de la ciudad histórica ${ }^{38}$. De hecho, a partir de 1980, las promociones de vivienda protegida (es decir, subvencionada para hacerla accesible a economías modestas) parecen haberse rarificado hasta desaparecer, tanto en centros como en barrios históricos. Por su parte, las operaciones de rehabilitación en centro histórico -en particular, las ARI-, al menos en Castilla y León, no han estado instrumentadas de manera adecuada al objetivo (nominal) de conservar la población residente, por lo que su eficacia en este sentido puede considerarse muy dudosa.

La acentuación de la evolución de la vivienda hacia los estratos altos probablemente no haya sido ajena a ciertas políticas que, en la senda de la llamada urban renaissance, se aplicaron con intensidad durante los años 1980 y 1990 en los centros históricos y sólo más tarde y de manera más fragmentaria en otras áreas de la ciudad:

${ }_{38}$ Un trabajo muy reciente sobre la Ciutat Vella de Valencia señala que la tendencia al alza inmobiliaria ha alcanzado incluso a este ámbito histórico que, afectada de graves problemas de degradación, había sufrido pocas sustituciones en las décadas del desarrollismo. GAJA I DíAZ, Fernando, Un futuro para el pasado. Un diagnóstico para la Ciutat Vella de València. Valencia: Universidad politécnica de Valencia, Instituto valenciano de vivienda y Colegio de ingenieros de caminos, canales y puertos de la Comunidad Valenciana, 2009, p. 314. 


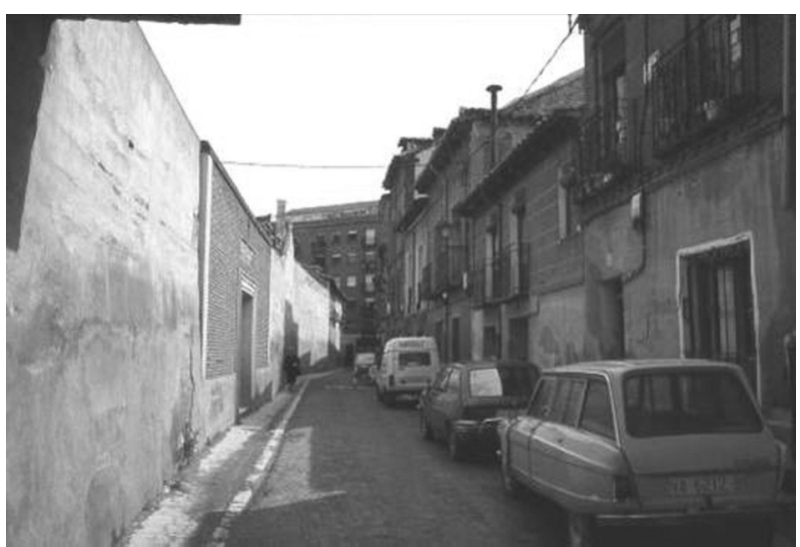

Figura 11. La calle Santo Domingo de Guzmán, en Valladolid, hacia 1975. Al fondo, un típico ejemplo de sustitución del caserío tradicional en el periodo (Foto: archivo del Instituto universitario de urbanística de la Universidad de Valladolid).

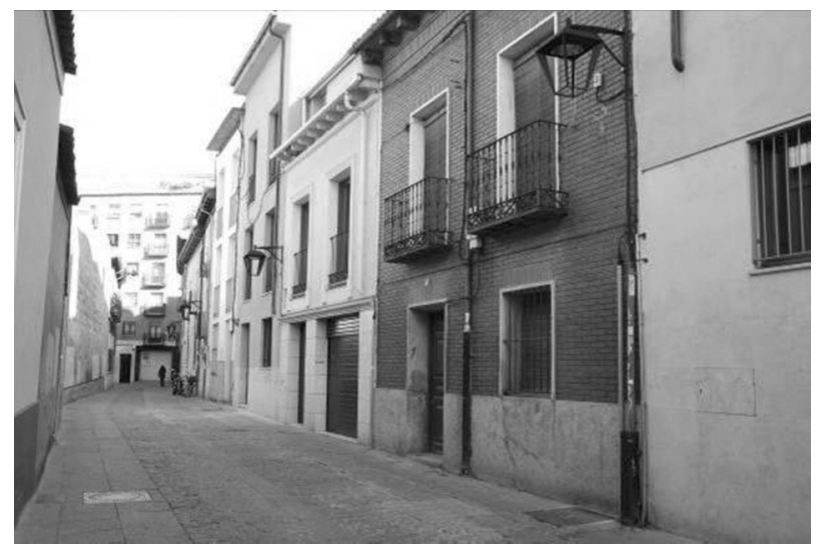

Figura 12. La calle Santo Domingo de Guzmán, en Valladolid, en 2008. La mayor parte de las edificaciones de la derecha de la imagen son intervenciones recientes de derribo y sustitución conservando la fachada.

- mejora sistemática del paisaje urbano y los espacios públicos, incluidas medidas de traffic calming ${ }^{39}$;

- apoyo al comercio minorista como «revitalizador» urbano (reurbanizaciones, peatonalizaciones, aparcamientos subterráneos... $)^{40} ;$ y

39 Accesibilidad y calidad ambiental: Perugia, Amsterdam, San Sebastián, Cuenca, Granada, Toledo, Bolonia, Grenoble, Fuenlabrada, Barakaldo, Gijón, Oviedo, Santiago de Compostela, Reims. I Congreso Movilidad y Calidad Ambiental en Centros Urbanos, Granada, Julio 1993. Madrid: Ministerio de Obras Públicas, Transportes y Medio Ambiente, 1995.

40 VILLAREJO GALENDE, Helena, «Privatizando las calles: el BID Bang», en VILADEVALL GUASCH, Mireia y CASTRILLO ROMÓN, María (coords.), El espacio público en la ciudad contemporánea: perspectivas críticas sobre su gestión, su patrimonialización y su proyecto. Valladolid: Universidad de Valladolid, 2010. 
- fomento del consumo cultural de masas y, en particular, del turismo cultural como factores de competición entre ciudades: restauraciones y tratamiento de entornos de monumentos ${ }^{41}$, nuevos equipamientos culturales (museos, auditorios, palacios de congresos...), etc.

Todo ello habría redundado en una acentuación y generalización en las ciudades históricas de los procesos de «elitización» y «terciarización» cultural y turística ya iniciados, al menos en áreas específicas, en la etapa anterior. La característica distintiva del proceso de conservación/destrucción de las ciudades históricas españolas en este periodo podría ser que la obtención de rentas ya no se basaría, como en el periodo anterior, en el incremento del volumen edificado sino en la rareza de la oferta, esto es, de la (revalorizada) condición «histórica» de esos espacios y de su localización selecta dentro del conjunto de una ciudad que, en ese momento, crece generalizadamente en extensión y dispersión territorial.

Por otro lado, si bien la presencia sensible de la arquitectura contemporánea habría tendido a reducirse en los centros históricos a partir de 1980, también sería perceptible una tendencia de visibilización, en este caso selectiva, de una arquitectura contemporánea de alta carga simbólica cuya calidad se pretende avalada por el recurso a la autoría de arquitectos de gran prestigio ${ }^{42}$.

Esta reciente irrupción de los lenguajes arquitectónicos contemporáneos en la escena urbana de las ciudades históricas, incluso en el corazón mismo de los conjuntos declarados o en el entorno de los monumentos más relevantes, constituye, en realidad, como ya hemos visto, una reaparición. Lo peculiar en este momento es esa visibilización selectiva vehiculada por impactantes edificios culturales, lo que no ha obstado para la expresión de la arquitectura contemporánea, ocasionalmente, en edificios residenciales y, de manera sistemática, también en remodelaciones de espacios públicos.

Tomando de nuevo como ilustración las ciudades de Castilla y León, puede reconocerse con Juan Luis de las Rivas que:

«En los últimos años, la inversión en los centros históricos de Castilla y León, en la rehabilitación de edificaciones y en el rediseño de los espacios públicos, es mayor que la realizada en los doscientos años anteriores. Se trata de un esfuerzo extraordinario ${ }^{43}$.

41 DE SALLE, Jean (ed.), Les monuments et leurs abords, entre conservation et développement: l'exemple des villes de Bordeaux, Luxembourg, Mons et Valladolid. Bruxelles: Société d'Architecture, de Rénovation et d'Urbanisme, [2000].

${ }_{42}$ No puede decirse que es este un fenómeno exclusivamente español. De hecho, la primera referencia cronológica bien podría ser el Centre Pompidou en el Beaubourg parisino. Y los ejemplos se multiplican por toda Europa en número y audacia. Uno de los que han alcanzado recientemente más eco es la intervención de Meyer en el Ara Pacis de Roma.

43 RIVAS, Juan Luis de las, «Los conjuntos históricos y sus paisajes. Notas para la puesta en valor del patrimonio urbano de Castilla y León», en RIVAS, Juan Luis de las (coord.), Atlas de Conjuntos Históricos de Castilla y León. Ob. Cit., p. 18. 
Fruto de este impulso inversor, han sido erigidos muchos edificios que han alcanzado un cierto reconocimiento de la crítica arquitectónica especializada. Sin aspirar a agotar el inventario posible, se pueden citar, en Salamanca, el Palacio de Congresos de Navarro Baldeweg (1985-1992), posiblemente factor clave de la recualificación residencial y social de uno de los entornos más degradados del recinto histórico de la ciudad (Figura 13); en Ávila, la controvertida remodelación de la Plaza de Santa Teresa o del Mercado Grande (2004) realizada bajo la autoría de Rafael Moneo (Figuras 14 y 15); y, en Zamora, entre otros, el Museo Arqueológico (1992-1996), proyectado por Mansilla y Tuñón. Se trata de edificios públicos que sancionan una (re)valorización cultural y de centralidad del ámbito urbano en el que se localizan y, con ello, también su revalorización social e inmobiliaria. Se inscriben así en el proceso de conservación/destrucción de la ciudad histórica con una nueva lógica que no se basa ya en derribos sistemáticos y sustituciones totales sino que tiene un carácter mucho más "selectivo», tanto en relación con las intervenciones edificatorias como en cuanto al sentido de los cambios introducidos.

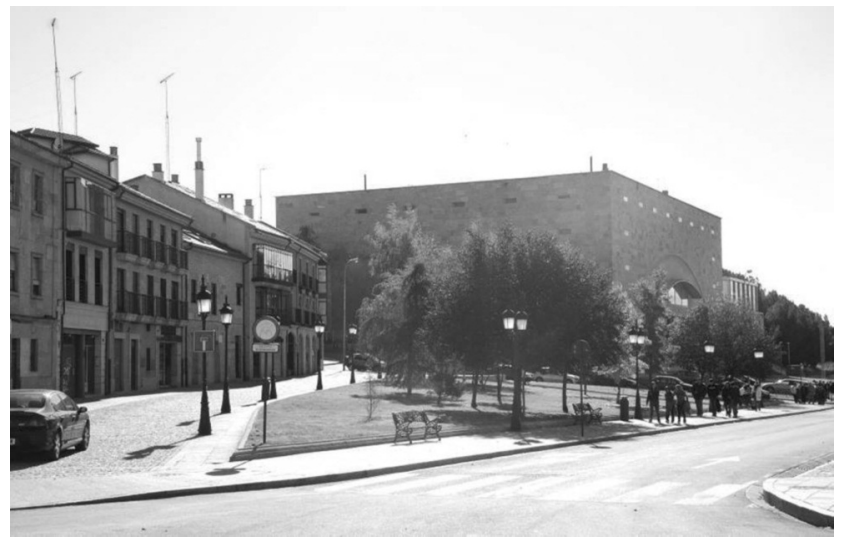

Figura 13. Palacio de Congresos de Salamanca, obra de Juan Navarro Baldeweg.

Esta reformulación reciente de los mecanismos de conservación/destrucción mantiene una relación compleja con la valoración de los centros históricos. En primer lugar, las arquitecturas contemporáneas de prestigio contribuyen al reconocimiento patrimonial del conjunto del entorno edificado desde la perspectiva monumental ya consolidada, pero con matices. La valoración se mantendría centrada en el valor estético o histórico de las construcciones, especialmente las emblemáticas del poder, pero reuniendo, junto al patrimonio antiguo (generalmente declarado), el «patrimonio contemporáneo» compuesto por esos edificios singulares que participan de una cierta monumentalidad que les confiriere, no sólo un uso y una configuración extraordinarios, sino también una firma rutilante en el firmamento de los arquitectos de prestigio en el universo mediático, esto es, una autoría a la que, más allá de la calidad de cada obra concreta y de su devenir temporal, se le ha asig- 
nado el marchamo de la representatividad memorial de la arquitectura del momento y, con ello, cada vez más, la condición de reclamo turístico-cultural.

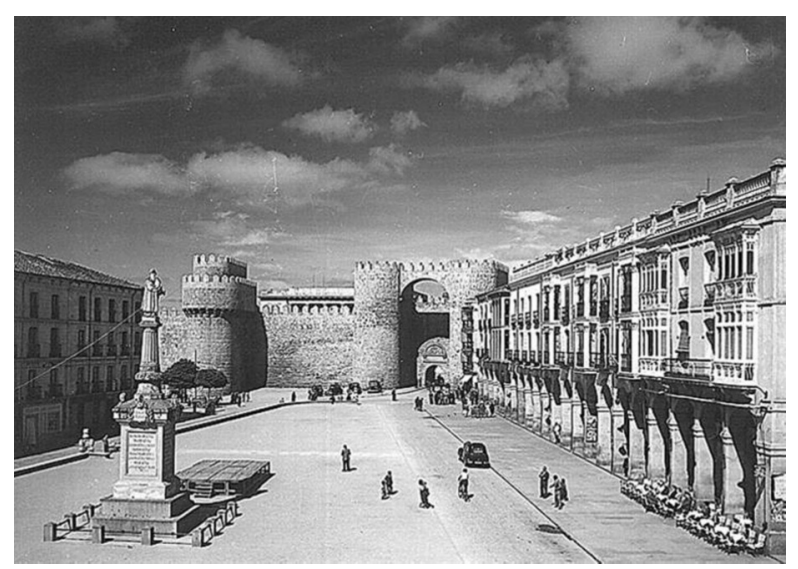

Figura 14. Plaza de Santa Teresa o del mercado grande, en Ávila. Imagen histórica (Fuente: RIVAS, Juan Luis de las (coord.), Atlas de Conjuntos Históricos de Castilla y León. [Valladolid], Consejería de Cultura y Turismo, [2009]).

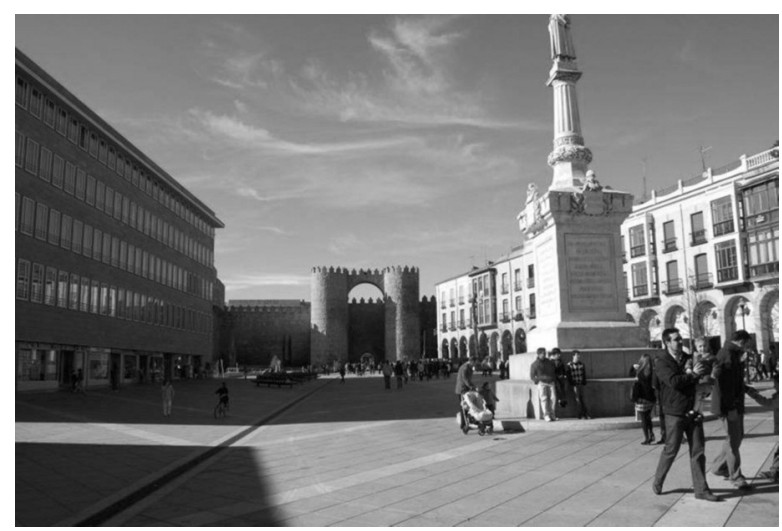

Figura 15. Vista actual de la Plaza de Santa Teresa (Ávila) tras la remodelación proyectada por Rafael Moneo.

No son raras las ocasiones que en las propuestas lanzadas desde esta perspectiva monumental o «avanzada» requieren del empleo de mecanismos de excepción para acometer este tipo de intervenciones extraordinarias en ámbitos donde, generalmente, los criterios de protección del «ambiente histórico» (alturas, alineaciones, materiales y composición de fachadas...) han llegado a ser objeto de una fuerte institucionalización sancionada tanto por la normativa como por la opinión pública más extendida. A menudo, esos grandes edificios públicos «de autor» encuentran resistencias provenientes de las corrientes monumentalistas más tra- 
dicionales, reacias a la introducción de lenguajes arquitectónicos poco miméticos con los entornos urbanos patrimoniales. Pues bien, en este género de conflictos suele cobrar toda su dimensión el recurso a la autoría arquitectónica de prestigio, que no sólo constituye un aval de monumentalidad y de afluencia de turistas, sino que también reviste la virtualidad de acallar o, al menos, minorar, con el argumento de la excelencia arquitectónica, las reticencias y objeciones que pudieran surgir en torno a la pertinencia de una determinada intervención contemporánea en un tejido urbano histórico considerado valioso.

Por otro lado, entre las arquitecturas contemporáneas de prestigio que expresan el momento actual del proceso de conservación/destrucción de la ciudad histórica en España, es posible observar una preferencia por los equipamientos culturales (museos...) u otros usos de centralidad. Dejando al margen la cuestión del ilusorio carácter «milagroso» mencionado al inicio de este artículo, lo cierto es que, en el caso de la ciudad histórica, esta tendencia nutre y, al tiempo, se nutre de la progresiva revaloración social y cultural de estos espacios, que viene operando en el sentido de su conversión en espacio de excepción, centro de las actividades turísticas y culturales, y área residencial exclusiva, presumiblemente para hogares pequeños de clase media y alto capital escolar. Con ello, además, se marginan y, a la larga, se inviabilizan otras posibles interpretaciones más atentas al valor de uso del patrimonio, a la contribución de los tejidos históricos al reequilibrio social y funcional de la ciudad, etc.

\section{CONCLUSIONES}

La concepción del patrimonio urbano que ha operado en la política urbanística ha estado sometida a la primacía de las consideraciones históricas y estéticas que dominaban, dentro de la política patrimonial, la valoración, primero, de los conjuntos histórico-artísticos y, después, de los conjuntos históricos. Tanto en los conjuntos declarados como en los centros históricos reconocidos como tales, se han marginado otras caracterizaciones del patrimonio urbano que lo relacionarían necesariamente con un medio social específico y concreto, distinto de los sectores de la demanda inmobiliaria más solvente, la única efectiva hoy sobre esas áreas. El peso de esta influencia habría tenido consecuencias importantes.

Por un lado, habría dado primacía a una interpretación del patrimonio urbano como «artefacto ahistórico» (Alvarez Mora), es decir, extraído (o al menos así se pretende) del devenir histórico. Con ello, se ignora precisamente que la existencia actual de esos bienes patrimoniales corresponde a su adaptación dentro del proceso evolutivo general en el que han estado inmersos. Las declaraciones patrimoniales parecen haber pretendido paralizar este proceso histórico en un momento dado, al menos en lo que se refiere a los bienes tutelados, negando la historicidad del presente y la pertinencia de su adaptación contemporánea, e incurriendo en importantes contradicciones, puesto que, en la práctica, la propia acción de conser- 
vación suele llevar implícita una adaptación —y no pequeña- a las exigencias del tiempo presente y, más concretamente, de la economía del turismo cultural que, en España como en otros muchos países, al calor de esa conservación «pasiva», se ha venido enseñoreando de buena parte del patrimonio urbano ${ }^{44}$.

En segundo lugar, ha legitimado procesos de conservación parcial (de áreas urbanas muy limitadas o de partes concretas de lo edificado) compatibles con la destrucción del patrimonio urbano tomado globalmente. Así, bajo diferentes modalidades, y pese al auge de las políticas conservacionistas, los procesos de destrucción del patrimonio urbano se han mantenido abiertos hasta la fecha. En su expresión actual, sus efectos son mucho menos perceptibles sobre las edificaciones que sobre la realidad social y económica, donde probablemente hayamos asistido a una sustitución casi total del sustrato complejo y heterogéneo que había alimentado durante siglos a la ciudad (histórica). Lo que puede resultar paradójico es que la patrimonialización que pretendía la «preservación» y «rescate» de esos ámbitos habría coadyuvado a la construcción de la interpretación que, puesta al servicio de las exigencias del mercado residencial de alta gama, el cultural y el turístico, ha alimentado esa sustitución.

La arquitectura contemporánea de prestigio, uno de los orgullos de las políticas urbanísticas recientes sobre los centros históricos, ha venido a cubrir otro papel importante en el proceso aquí esbozado para las ciudades y pueblos más dinámicos, operando efectivamente en su conversión en espacios de privilegio, con usos de carácter exclusivo que acentúan la centralidad de los ámbitos históricos y que aumentan las distancias económicas y sociales —en definitiva, las desigualdades urbanas - entre esos lugares «de la cultura» y el resto de la ciudad. Por esta vía, la desvinculación entre las áreas urbanas patrimoniales o «monumentales» y el conjunto de la ciudad queda relacionada con buena parte de los desequilibrios territoriales que caracterizan a ésta última.

En este contexto, la arquitectura contemporánea expresada en grandes equipamientos culturales insertos en tramas urbanas históricas, más allá de polémicas academicistas y mediáticas, y al margen de su posible interés disciplinar, puede ser sometida a una interpretación como herramienta privilegiada de reforzamiento de las dos tendencias que estarían procediendo a una reconstrucción social y económica de los centros urbanos y, con ello, al desequilibrio de las ciudades: la «elitización» (predominio progresivo de las clases medias) y la «terciarización» de las actividades económicas, en particular, el predominio de las ligadas al consumo cultural y el turismo.

La ubicación de grandes equipamientos urbanos o regionales en la ciudad histórica puede interpretarse como un instrumento de refuerzo de su carácter central y de revalorización social y, en consecuencia, inmobiliaria de sus entornos

44 VILADEVALL I GUASCH, Mireia, «La utopía de lo urbano patrimonial o herejías sobre el patrimonio urbano», en VILADEVALL, M. y CASTRILLO, M,(coord.), El espacio público... 
(entornos que, con mucha frecuencia, como resultado de la construcción del equipamiento han sido «rescatados» de una situación de degradación urbana, esto es, de su minusvaloración inmobiliaria). En este sentido, también se puede interpretar como un mecanismo genérico de recomposición urbana en un sentido de exclusividad social y de reconstrucción de los valores simbólicos de la ciudad histórica allí donde estos no correspondían a los de un espacio de prestigio. Por otro lado, la calidad contemporánea de la arquitectura, traducida operativamente en el recurso a arquitectos de renombre, tiene, en el contexto actual, evidentes efectos mediáticos que operan claramente a favor del redoblamiento de la efectividad del instrumento.

Lo que interesa a este respecto no es tanto el (supuesto) carácter «milagroso» para las economías urbanas de esas arquitecturas contemporáneas en tejidos históricos sino la comprensión del conjunto de condiciones y circunstancias que han posibilitado su materialización, y el alcance real de ésta en su verdadera escala, esto es, la del conjunto de la ciudad, no sólo la «histórica». Obvia decir que los efectos apuntados de «elitización» y «terciarización» de la ciudad histórica y su contribución a la segregación socio-espacial y al desequilibrio funcional de la ciudad, no son consecuencia necesaria del recurso a la arquitectura contemporánea, sino de su instrumentalización en el marco de esas políticas urbanas que obran desde presupuestos de excepción. Sería pertinente, en este sentido, preguntarse cómo, en qué condiciones, la arquitectura —necesariamente contemporáneapodría contribuir hoy a reconstruir globalmente la historicidad de nuestras ciudades, a rescatar los valores del patrimonio urbano básico que es la ciudad en toda su complejidad (civitas, urbs y polis).

Puede apuntarse también que las políticas urbano-patrimoniales más recientes y las intervenciones arquitectónicas contemporáneas a ellas asociadas habrían sido legitimadas, en buena medida, por un cambio cultural operado en las últimas décadas, identificado con el «deslizamiento del concepto de patrimonio» hacia lo edificado no monumental y hacia lo moderno, identificado por Ortega Valcárcel ${ }^{45}$. Cabe conjeturar que, al tiempo que el concepto de patrimonio se ampliaba, el cambio social hacia el dominio de las clases medias y el cambio funcional hacia actividades terciarias, especialmente, culturales y turísticas, vehiculados ambos por la revaloración cultural, se habrían ido generalizando al conjunto de las áreas patrimoniales, llegando a conquistar incluso -y esto parece una tendencia claramente emergente en Europa- determinados barrios populares ${ }^{46}$ y enclaves industriales urbanos ${ }^{47}$.

45 ORTEGA VALCÁRCEL, José, «El patrimonio territorial: el territorio como recurso cultural y económico», Ciudades, 4 (1998), pp. 33-48.

${ }^{46}$ Véase, por ejemplo, el caso de los barrios populares de los $18^{\circ}$ y $19^{\circ}$ arrondissements de París, estudiados por Anne Clerval en «La réhabilitation urbaine à des fins de revalorisation foncière. Le cas de la France à partir de l'exemple de Paris", informe elaborado en el marco del documento Integrated Urban Regeneration in the European Union, preparatorio del Toledo Informal Ministerial Meeting on Urban Development de junio de 2010, pp. 694-708.

http://www.vivienda.es/es/jornadas/TOLEDO/ANNEXES\%20TO\%20THE\%20SURVEY\%20vs\%20English.pdf (Consultado: 18 de octubre de 2010).

47 GARNIER, Jean Pierre, «La ville recyclée», La Brique, no 18, novembre 2009. También en: http://blog.agone.org/post/2010/01/26/La-ville-recyclee (Consultado: 13 de diciembre de 2010). 
Tomados en conjunto, los procesos aquí revisados apuntan a que, pese a la progresiva omnipresencia de los discursos patrimonialistas, lo que es efectivo es la primacía del valor de cambio en la interpretación de los bienes patrimoniales. Los procesos de «elitización» y de «terciarización» cultural y turística de los tejidos históricos pueden entenderse como dos modalidades de conversión de éstos en «mercancías culturales». La amenaza de mercantilización del patrimonio edificado, insistentemente denunciada por Françoise Choay ${ }^{48}$, se estaría realizando hoy, bajo estas formas, en muchas ciudades históricas que ya no son hábitat sino de los reducidos grupos sociales que pueden pagar una vivienda en entornos urbanos de una rareza y exclusividad irrepetibles, y de las empresas culturales, hosteleras y de comercio selecto. Desde mediados del siglo XX, los conceptos, normas, mecanismos y procesos hasta aquí apuntados, desarrollados en el seno - no huelga decirlo- de sociedades capitalistas, habrían coadyuvado a - cuando no se hubieren puesto directamente al servicio de-esta mercantilización que permite comprender, en última instancia, los límites y alcances de la aparentemente contradictoria inserción de arquitecturas contemporáneas en entornos urbanos históricos protegidos.

\section{AGRADECIMIENTOS}

Queremos agradecer colaboraciones de todo tipo a los compañeros del IUU involucrados en las distintas líneas y proyectos de investigación relacionados con los contenidos de este artículo: Alfonso Álvarez Mora, Juan Luis de las Rivas Sanz, Goyo Vázquez Justel, Manuel Domingo Vaquero, Enrique Rodrigo González y José Luis Lalana Soto, y también Luis Santos Ganges, Félix Iglesias Escudero, Inés Cieza, Andrea González, Carmen Martín y Henar Sanz.

Valladolid, 30 de diciembre de 2010.

María A. Castrillo Romón y Marina Jiménez Jiménez

${ }^{48} \mathrm{CHOAY}, \mathrm{F}$. , Alegoría... y CHOAY, Françoise, Le patrimoine en questions. Anthologie pour un combat. Paris: Seuil, 2009. 